\title{
Intelligent Decision Support Model Based on Neural Network to Support Reservoir Water Release Decision
}

\author{
Wan Hussain Wan Ishak ${ }^{1}, \mathrm{Ku}$ Ruhana Ku-Mahamud ${ }^{1}$, and Norita Md Norwawi ${ }^{2}$ \\ ${ }^{1}$ College of Arts and Sciences, Universiti Utara Malaysia, UUM Sintok, Kedah, Malaysia \\ \{hussain, ruhana\} @uum. edu.my \\ ${ }^{2}$ Faculty of Science and Technology, Universiti Sains Islam Malaysia, Nilai, Ng Sembilan, \\ Malaysia \\ norita@usim.edu.my
}

\begin{abstract}
Reservoir is one of the emergency environments that required fast an accurate decision to reduce flood risk during heavy rainfall and contain water during less rainfall. Typically, during heavy rainfall, the water level increase very fast, thus decision of the water release is timely and crucial task. In this paper, intelligent decision support model based on neural network (NN) is proposed. The proposed model consists of situation assessment, forecasting and decision models. Situation assessment utilized temporal data mining technique to extract relevant data and attribute from the reservoir operation record. The forecasting model utilize $\mathrm{NN}$ to perform forecasting of the reservoir water level, while in the decision model, $\mathrm{NN}$ is applied to perform classification of the current and changes of reservoir water level. The simulations have shown that the performances of $\mathrm{NN}$ for both forecasting and decision models are acceptably good.
\end{abstract}

Keywords: Emergency Management, Intelligent Decision Support System, Neural Network, Forecasting.

\section{Introduction}

In emergency situation, "decisions must be made in human perceptual timeframes under pressure to respond to dynamic uncertain conditions" [1]. A failure to response early to the emergency situation could cause severe damages and possibility of loss of life. Flood for example, could strike without warning due to natural circumstances such as climate changes. This hazard can cause direct effect to the society such as loss of human lives and damage to the physical structures.

Moreover, "information can be inaccurate or obtained from multiple sources that are inconsistent with each other, resulting in uncertainty and information overload for the user" [2]. Uncertain conditions are very difficult to interpret as the data are vague and incomplete. Access to the data is difficult [2] and the presentation of the data is quite poor; difficult to interpret and understand [1]. In addition, the interdependence between subsequent decision and the time constraint [3] increase the complexity of 
the decision process. The complexity of the problem required experience decision maker to make an accurate decision [4].

An intelligent decision model, namely intelligent decision support system (IDSS) is one of the potential solutions to support decision maker in emergency situation. IDSS is an integration of DSS and Artificial Intelligence (AI). Reservoir management has been one of the potential applications in IDSS due to the complexity of the operation, expert knowledge requirement and intelligent judgement [5].

Reservoir plays an important function in water resources planning and management. Typically two categories of reservoir have been established around the world namely single and multi-purpose reservoir. Reservoir operation is influenced by it purposes [6]. The operation problem for a single-purpose reservoir is to decide the adequate release volume so that the benefits for that purpose are maximized. The operation of multi-purpose reservoir inherit the same problem, additionally, the release need to be optimally allocated among purposes. The compatibility of the purposes will affect the coordination effort and thus will increase the complexity of the reservoir operation.

The operation of multi-purpose reservoir with flood control and water supply purposes is one of the complex and dynamic problems in reservoir operation. During heavy rain, reservoir needs to impound water and release them gradually to maintain downstream discharges within the safe carrying capacity of the channel [6] and minimize the downstream damages and to ensure dam safety [7].

Conversely, during less intense rainfall, the reservoir has to impound adequate water to maintain its water level without affecting its release for water supply. Therefore, the realistic reservoir operating policies for water allocation and the optimal reservoir releases need to be established [8]. The computer based decision support system also needs the capability to adapt to the changes [2] as climate change is one of the greatest threats of this century [9].

\section{Reservoir as Structural Mitigation during Emergency Situation}

The reservoir is a physical structure such as pond or lake either natural or artificially developed to impound and regulate the water. It has been used as one of the structural approaches for flood defence and water storage. Flood defence is a mechanism use to modify the hydrodynamic characteristics of river flows in order to reduce the flood risk downstream [6]. Water storage is to contain water in order to maintain water supply for it use such as in agriculture, domestic and industry.

Mitigation is one of the tasks in emergency management cycle. Mitigation is a process of reducing the risk of the disaster. Mitigation related to water disaster, can be divided into structural and non-structural approaches [10]. Structural approach such as defence mechanism [6] is related to physical control of the emergency situation. Reservoir is one of the defence mechanism for both flood and drought disaster.

Defence mechanism is use to modify the hydrodynamic characteristics of river flows and coastal waters [6]. The defence can be achieved by traditional water engineering methods and by water abatement methods. Traditional water engineering methods using 'hard' defences include river channel modifications or using artificial 
materials like concrete which specifically shaped and designed to control water flows. While, water abatements methods using 'soft' defences rely on essentially natural materials, whether of geological or biological origin and existing environmental processes. One of the popular defence mechanisms that are currently being used by many countries in the world is dam. The use of dam for flood mitigation is aim to impound water in a reservoir during periods of high flow in order to maintain safe downstream discharges [6]. The opening of the dam's spillway gate must be adequate to ensure that the reservoir capacity will not over its limits and the discharges will not cause overflow downstream. During drought, the reservoir needs to impound water and release adequately to fulfil its purposes.

A reservoir system can be divided into four components namely, upstream, reservoir catchment, the spillway gate, and downstream (Figure 1). The upstream consists of one or several rivers that carry the water into the reservoir. The water is stored in the reservoir catchment before releases through the spillway gate to the downstream. This kind of system is designed to ensure that during heavy rainfall, the upstream water flow does not directly flow to the downstream. The reservoir system will control the water flow and the releases within the safe carrying capacity of the downstream river [6], thus minimize the downstream damages [7].

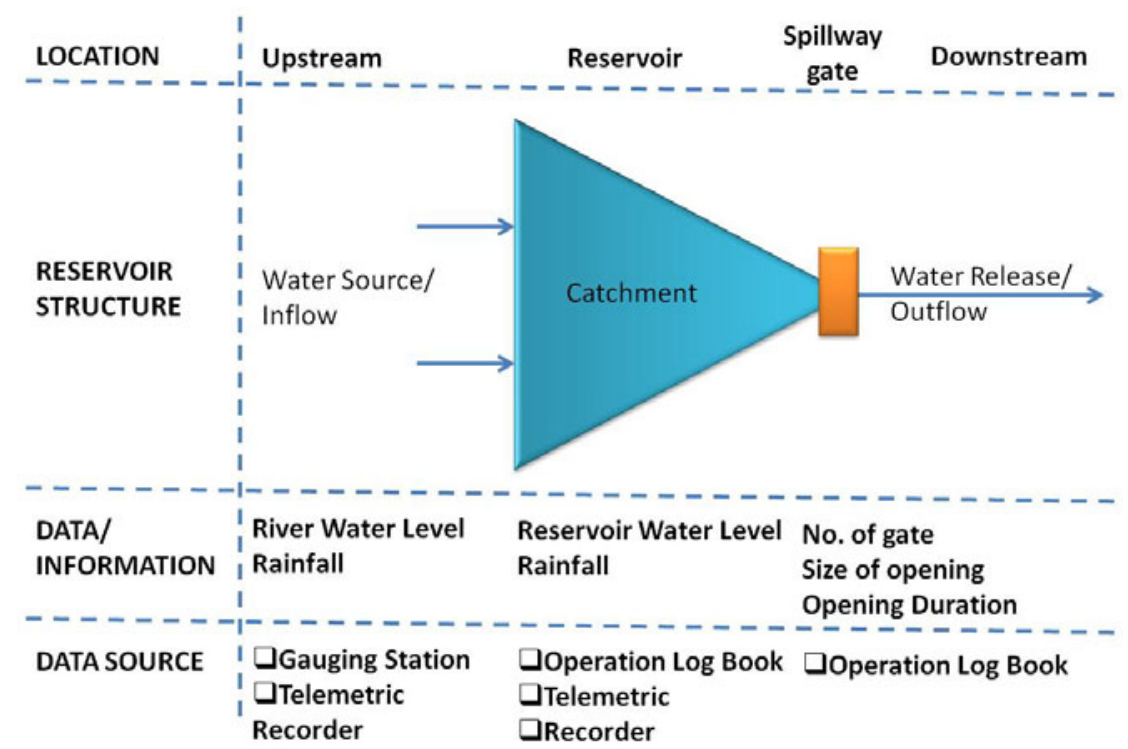

Fig. 1. Conceptual Model of Reservoir System

As shown in Figure 1, each component of the reservoir system is associated with data or information. The water level and rainfall are prevalence in both upstream and the reservoir catchments. These data are recorded hourly using the telemetric recorder situated at the strategic location of both upstream river and reservoir. 
Additionally, manual reading of the rainfall also recorded through the gauging stations. At the spillway gate, the typical data are number of gate opened, the size of opening, and the opening duration. These data are recorded manually by the reservoir operator in the operation log book.

During both flood and drought situations, the decision to open and close the water gate is a critical action need to be undertaken by the dam operator as late decision will not only causing flood downstream but also will damage the dam structure. Releasing the water earlier before the reservoir reaching its full capacity might reduce the flood risk downstream. However, one cannot be sure that the water release will be replaced by the new one to serve it usage during less intense rainfall. As for multi purpose dam low water in the reservoir will cause conflict on its usage. Researchers believe that the use of forecasting and warning system might improve the dam operation and decision [10].

Forecasting and warning system are example of the non-structural approach. Nonstructural approach is non-physical control in which the emergency is control using a procedure. Example of the non-physical control is flood insurance [11], flood zoning [12] and flood forecasting [13]. In term of implementation, structural solution cost higher compare to non-structural solution. However, non-structural solution is constraint to its political implementation [10].

The combine implementation of structural and non-structural approach is vital to avoid casualty and false sense of security at storage [14]. Structural approach such as dam is a solid structure that holds water for a certain period or at maximum reservoir water level. In practice, the water release or the gate opening decision depends on the operating rules [15]. These rules are static and do not consider the dynamic nature of the hydrology systems. Therefore, non-structural approach such as forecasting is vital to support the water release or the gate opening decision. The dynamic of the forecasting system will be able to cope with the event frequency and triggered alert to the authority when the situation is at the severe level. Flood forecasting is significant to cope with the great floods [16].

\section{Intelligent Decision Support System Framework}

Intelligent Decision Support System is an integration of DSS and artificial intelligence (AI) technology combining the basic function of DSS and reasoning capabilities of AI techniques [17]. AI is viewed as a system that has the ability to "think" and "act" [18]. Based on discussion in Russell and Norvig, AI definitions can be viewed into two dimensions (Figure 2). In the first dimension, AI can be regarded as a system that think like humans or that thinks rationally. In second dimension, $\mathrm{AI}$ is viewed as a system that acts like humans or that act rationally.

Guerlain et al. [19] has identified six characteristics of successful IDSS; interactivity, representation aiding, event and change detection, error detection and recovery, information extraction and predictive capabilities. Interactivity is the interaction between the system and user. The IDSS is expected to support interactivity, in which user can present the input and receive the output as the feedback. The presentation of the information on the interface should be readable and understandable by the user. The system 
should be aid the user and explain the output or how it derives the conclusion. The intelligent capability of the system should be intelligent enough to detect and adapt the changes in user input or the surroundings which might influence the operation or the processes in the system decision making. The system should be prone to error by integrating the error detection and recovery facility.

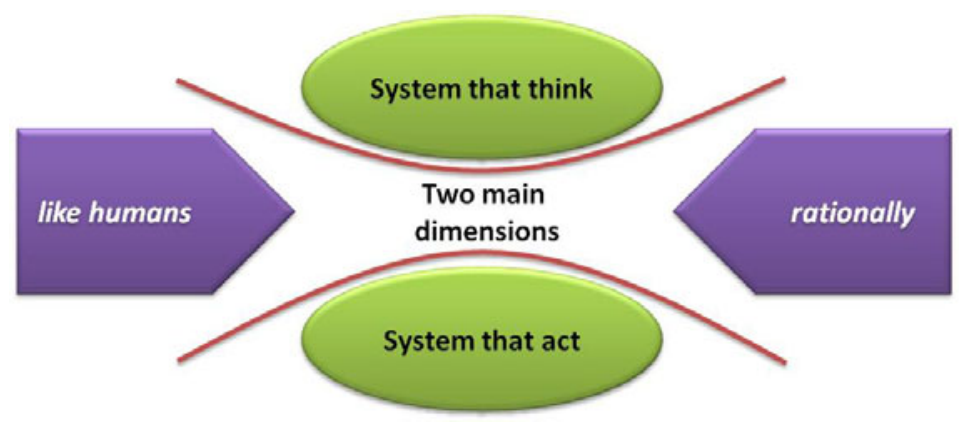

Fig. 2. Dimension in AI Technology

The most important component of the IDSS is the information extraction and predictive capability. Information extraction is the capability to extract the useful information from the abundance of information. This information will serve as the input to the IDSS or to be represented to the user in a meaningful format. The IDSS predictive capability will use and analyze the information into a pattern by which represents a trend of the event. This trend will be learned and to be used to predict the future event. These facilities exhibit intelligent behaviour of the IDSS and very useful in assisting the decision maker.

The theoretical framework in Figure 3, shows the mapping between the conceptual and computational level, and the relationship between the emergency environment and the real world practice. The emergency situations inherit several characteristics namely, dynamic, urgency, uncertain, complex, high risk, and previous action dependent. These characteristics are also a part of the problem that solved through naturalistic decision making (NDM). This problem can be solved using adaptive and dynamic system approach: Intelligent Decision Support System (IDSS). The proposed IDSS consists of three main sub-models: situation assessment model, expectancy forecasting, and decision model. Situation assessment model can utilized data mining technique to extract temporal data sets from the data sources. Expectancy forecasting model is to forecast the future effect of the known factors. Neural network can be used as the forecasting technique. The decision model will produced the final output of the IDSS. In this model, expert system, fuzzy logic or neural network can be utilized as the decision engine. 


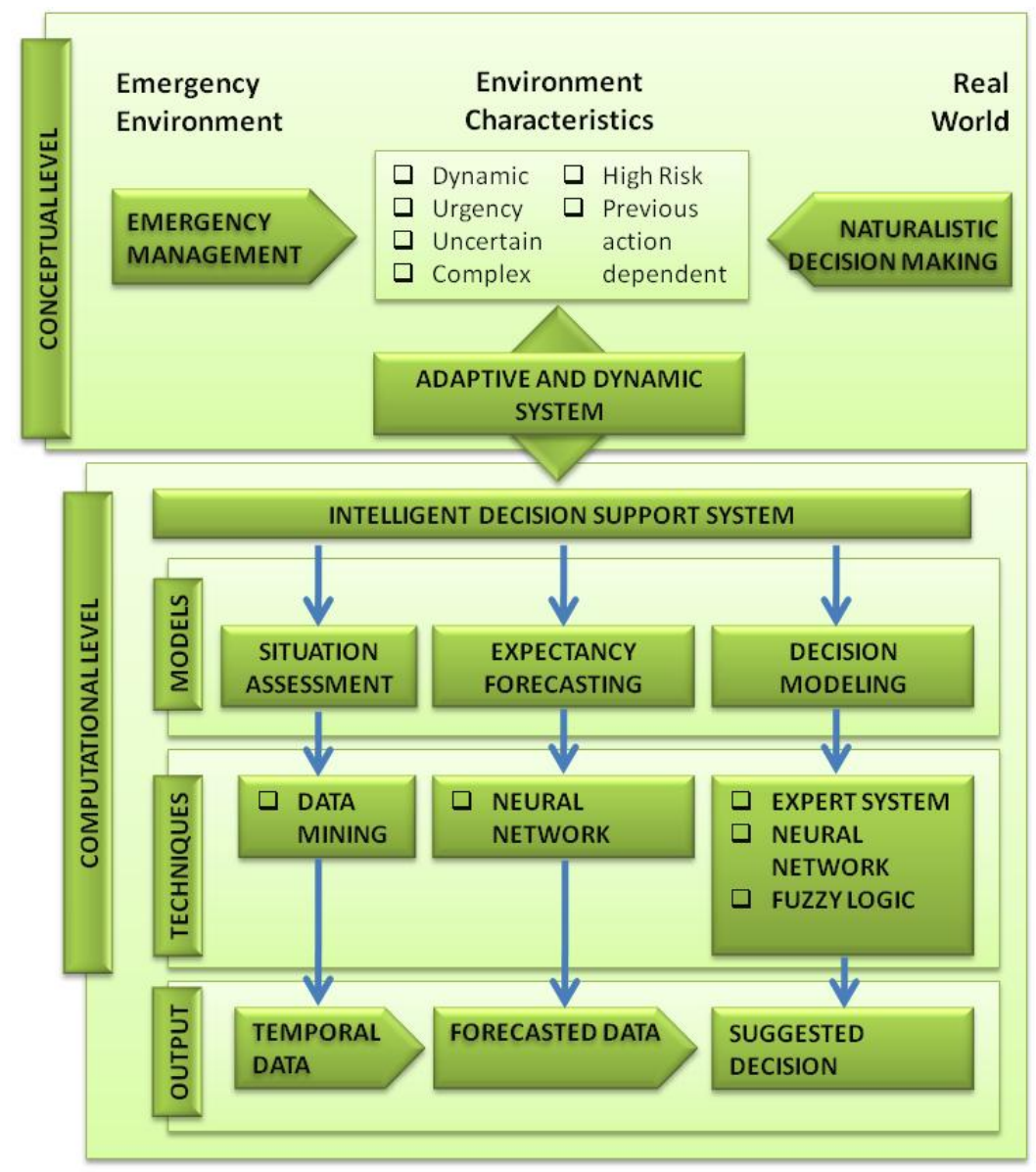

Fig. 3. Theoretical Framework

Figure 4 shows the conceptual of model IDSS for reservoir operation. As shown in Figure 4, data mining will combine both hydrological and operational data and extract the temporal data that maintain the temporal relationship of the data. The extraction process will include data integration, data preprocessing, temporal data mining, and post processing. The extracted data will be feed into water level forecasting model, which will calculate the probability of the rising of reservoir water level using neural network. The result of this model is the forecasted water level at time $t+1$. The forecasted data will be used in the decision model. Finally, the gate opening decision will be produced. 


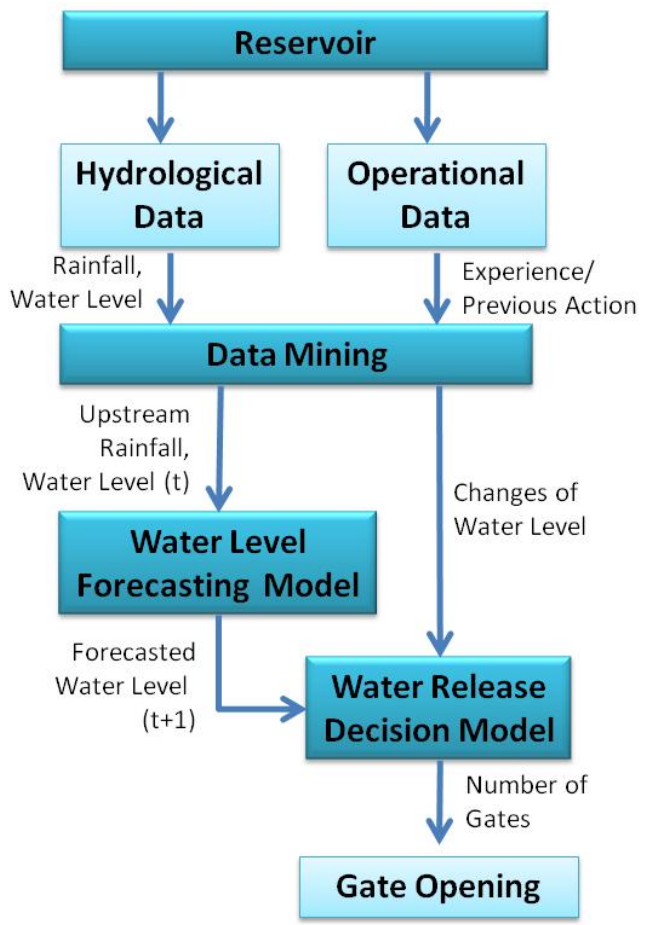

Fig. 4. Conceptual Model of IDSS for Reservoir Operation

\section{Neural Network Application in Reservoir Operation}

Neural network $(\mathrm{NN})$ is a mathematical computational model that imitates the biological neuron capability. One of the main features of neural network is it be able to learn a pattern and apply the "knowledge" to the similar pattern. This capability enable neural network to be used to solve wide range of problems including forecasting and classification problem. In the application of reservoir operation and management, NN has been applied for various simulation and optimization problem. Table 1 summarizes some of the related studies and NN model implemented.

Table 1. Related Studies and NN Application in Reservoir Operation and Management

\begin{tabular}{|l|l|l|}
\hline Studies & Application & NN Model \\
\hline Hu et al., [20] and & River Flow Prediction & Range-Dependent NN(RDNN) \\
\hline $\begin{array}{l}\text { Dibike } \\
\text { Solomatine [21] }\end{array}$ & $\begin{array}{l}\text { Multi-Layer Perceptron Network } \\
\text { (MLP) \& Radial Basis Function } \\
\text { Network (RBF) }\end{array}$ \\
\hline $\begin{array}{l}\text { Chang and Chen } \\
{[22]}\end{array}$ & Streamflow Prediction & $\begin{array}{l}\text { Counterpropagation Fuzzy-NN } \\
\text { (CFNN) }\end{array}$ \\
\hline
\end{tabular}


Table 1.(continued)

\begin{tabular}{|l|l|l|}
\hline Kisi [23] & Streamflow Prediction & Backpropagation NN \\
\hline Coulibaly et al. [24] & $\begin{array}{l}\text { Multivariate Reservoir Inflow } \\
\text { Forecasting }\end{array}$ & Temporal NNs \\
\hline Coulibaly et al. [25] & $\begin{array}{l}\text { Daily Reservoir Inflow } \\
\text { Forecasting }\end{array}$ & $\begin{array}{l}\text { Multi-layer Feed-Forward NN } \\
\text { (FNN) }\end{array}$ \\
\hline $\begin{array}{l}\text { Chang and Chang } \\
{[26]}\end{array}$ & $\begin{array}{l}\text { Prediction of Reservoir Water } \\
\text { Level }\end{array}$ & $\begin{array}{l}\text { Adaptive Network-Based Fuzzy } \\
\text { Inference System (ANFIS) }\end{array}$ \\
\hline $\begin{array}{l}\text { Lobbrecht and } \\
\text { Solomatine [27] }\end{array}$ & $\begin{array}{l}\text { Controlling the Polder Water } \\
\text { Levels }\end{array}$ & $\begin{array}{l}\text { ANN and Fuzzy Adaptive Systems } \\
\text { (FAS) }\end{array}$ \\
\hline $\begin{array}{l}\text { Solomatine and Xue } \\
{[28]}\end{array}$ & Flood Forecasting & $\begin{array}{l}\text { Multilayer Perceptron \& Hybrid } \\
\text { (M5 \& MLP) }\end{array}$ \\
\hline $\begin{array}{l}\text { Kumar et al. [29] } \\
\text { Standard Backpropagation } \\
\text { Algorithm }\end{array}$ \\
\hline $\begin{array}{l}\text { Chaves and Chang } \\
{[30]}\end{array}$ & $\begin{array}{l}\text { Flood Control Operation and } \\
\text { Conservation Operation } \\
\text { System }\end{array}$ & Evolving ANN \\
\hline
\end{tabular}

\section{Method}

In this study, standard backpropagation neural network with bias, learning rate and momentum are used in both forecasting and decision model. In forecasting model, neural network is used to train the rainfall data (at $t$ ) and to create a mapping with the reservoir water level at $t+1$. In the decision model, neural network is used to train the water level (at $t$ and $t+1$ ) and the changes of water level. The output produce by the decision model is the number of gate to be opened. The temporal information of the rainfall and water level data are preserve by using sliding window technique. Once data has been prepared, the training was conducted base on the standard training procedure.

\subsection{Case Study: Timah Tasoh Reservoir}

In this study, Timah Tasoh reservoir was used as a case study. Timah Tasoh reservoir is one of the largest multipurpose reservoirs in northern Peninsular Malaysia. Timah Tasoh located on Sungai Korok in the state of Perlis, about $2.5 \mathrm{~km}$ below the confluence of Sungai Timah and Sungai Tasoh. Timah Tasoh reservoir covered the area of $13.33 \mathrm{Km}^{2}$ with the catchment area $191.0 \mathrm{Km}^{2}$. Its maximum capacity is $40.0 \mathrm{Mm}^{3}$. Timah Tasoh reservoir serves as flood mitigation in conjunction to other purposes: water supply and recreation. Water from Timah Tasoh is used for domestic, industrial and irrigation.

\subsection{Data Preparation}

Reservoir water level is influence by a number of factors such as upstream rainfall, water flow, heat and temperature, and evaporation rate. However, technological and political constraints have limited the availability of the data. In this study, a total of 3041 daily data from Jan 1999 - April 2007 were gathered from the Timah Tasoh reservoir operation record. Timah Tasoh upstream rainfall was manually recorded 
through 5 upstream gauging stations. Rainfall observed from these stations will eventually increase the reservoir water level.

For the forecasting model, rainfall data from these stations and the current reservoir water level $(t)$ are used as the input data and the reservoir water level at time $t+1$ is used as the target. In the decision model the current water level $(t)$, tomorrow water level $(t+1)$, and the changes of water level at $t, t-1, \ldots, t-w$ were used as the input data, while the gate opening/closing at $t$ is used as the target. The constant $t$ and $w$ represent time and days of delays (which later represented as window size). Gate opening/closing value is in range of zero to six. Zero indicates gate is closed and values from one to six indicate the number of gates that are open. The change of this value implies the decision point. At this point window slice will be formed begin from that point and preceding to $w$ days according the window size.

Sliding window technique is used to capture the time delay within the data set. Sliding window technique was proven able to detect patterns from temporal data [31]. This process is called segmentation process. For both forecasting and decision model, nine data sets have been formed. Each data set represents different sliding size. Each sliding size represent time duration of the delays. For example, sliding size 2 represents two days of delays. Table 2 summarizes the number of instances extracted for each data set. Segmentation process for decision model will return a total of 124 instances. Redundant and conflicting instances are then removed.

Table 2. Data set and the number of instances

\begin{tabular}{cccc}
\hline \multirow{2}{*}{ Data Set } & \multirow{2}{*}{ Sliding Size } & \multicolumn{2}{c}{ Number of Instances } \\
\cline { 3 - 4 } & & Forecasting Model & Decision Model \\
\hline 1 & 2 & 2075 & 43 \\
2 & 3 & 2408 & 54 \\
3 & 4 & 2571 & 71 \\
4 & 5 & 2668 & 82 \\
5 & 6 & 2732 & 95 \\
6 & 7 & 2774 & 109 \\
7 & 8 & 2805 & 113 \\
8 & 9 & 2826 & 118 \\
9 & 10 & 2844 & 119 \\
\hline
\end{tabular}

Each data set consists of $N$ number of input columns and 1 output column. The output consists of 4 classes. The input is then normalized using Min-Max method (Equation $1)$ to transform a value $x$ to fit in the range $[C, D]$. Where, $C$ is the new minimum $(-1)$ and $D$ is the new maximum (1) values. In this study the new value is set in range of [1,1]. The output is encoded based on Binary-Coded-Decimal (BCD) scheme. BCD is preferably as the total number of output nodes can be reduced to the integer of $\log _{2} M$, where $M$ is the number of classes [32].

$$
\operatorname{New}(x)=\left[\frac{x-\min (x)}{\max (x)-\min (x)}\right] *(D-C)+C
$$


Each data set is then divided randomly into three data sets: training set (80\%), validation set $(10 \%)$ and testing set $(10 \%)$. Training set is used in the training phase of neural network, while validation set is used to validate the neural network performance during the training. Testing set is used to test the performance of neural network after the training has completed.

\subsection{Neural Network Modelling}

The aim of neural network modelling is to create a mapping between the input data and the target output. This mapping was established by training the neural network to minimize the error between the network output and the target (Equation 2). In this study, nine neural network models were developed for both forecasting and decision model. Each neural network model is trained with one data set. Each model is trained with different combination of hidden unit, learning rate and momentum. The training is control by three conditions (1) maximum epoch (2) minimum error, and (3) early stopping condition. Early stopping is executed when the validation error continue to arises for several epochs [33]. Fig. 5 shows the procedure for the neural network training. The aim of this procedure is get the neural network model that gives the best result.

$$
S E=\frac{1}{2} \sum_{k=1}^{p}\left(t_{k}-y_{k}\right)^{2}
$$

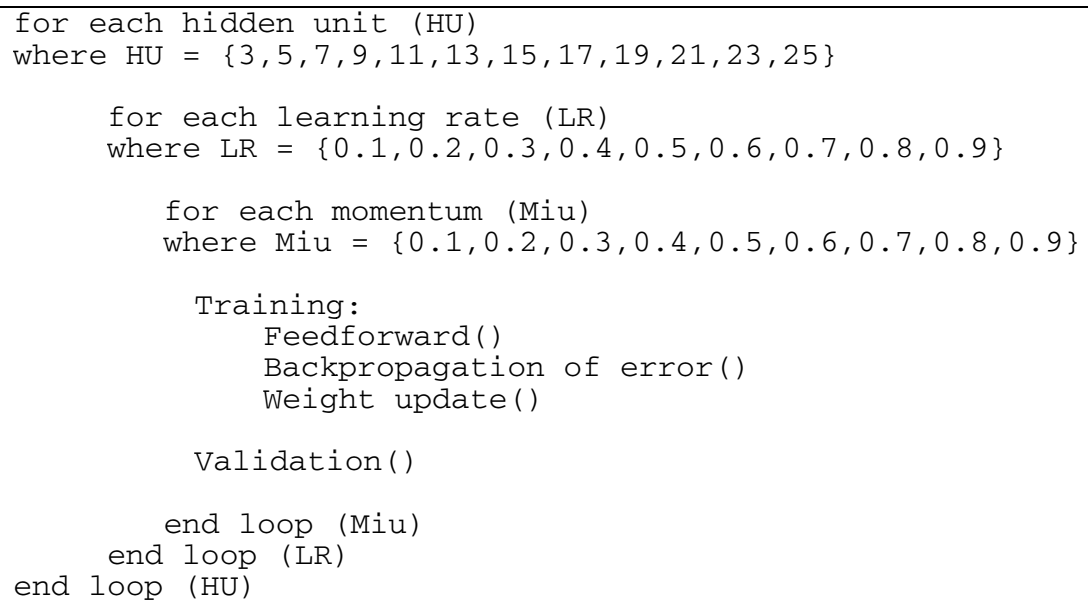

Fig. 5. Pseudo Code for Neural Network Training 


\section{Findings}

\subsection{Forecasting Model}

Table 3 shows the results for each data set after training and testing for the forecasting model. Overall the minimum training, validation and testing error are 0.461878 , 0.41825 and 0.416571 respectively. The best result achieved for training, validation and testing are $89.99 \%, 91.34 \%$ and $91.52 \%$ respectively. There is a small difference between the highest and lowest results achieve from training, validation and testing. The difference shows that neural network has learned the data quite well. Based on the results, data set 7 is chosen as the best data set for reservoir water level forecasting model. The result for training, validation and testing are 89.61, 91.34 and 90.75. Data set 7 was formed using sliding size 8 which contains 2805 instances.

Table 3. Results of Training, Validation and Testing

\begin{tabular}{ccrrrrr}
\hline \multirow{2}{*}{ Data Set } & \multicolumn{2}{c}{ Training } & \multicolumn{2}{c}{ Validation } & \multicolumn{2}{c}{ Testing } \\
& $(\%)$ & \multicolumn{1}{c}{ Error } & \multicolumn{1}{c}{$(\%)$} & \multicolumn{1}{c}{ Error } & \multicolumn{1}{c}{$\%)$} & \multicolumn{1}{c}{ Error } \\
\hline 1 & 87.48 & 0.785791 & 86.22 & 0.860958 & 89.26 & 0.667375 \\
2 & 87.92 & 0.58714 & 87.00 & 0.573727 & 87.56 & 0.586856 \\
3 & 87.65 & 0.599483 & 89.75 & 0.457907 & 89.36 & 0.490453 \\
4 & 89.45 & 0.492463 & 88.52 & 0.502691 & 90.76 & 0.444052 \\
5 & 89.50 & 0.483055 & 89.87 & 0.50378 & 90.36 & 0.503575 \\
6 & 89.43 & 0.480323 & 90.74 & 0.421007 & 89.05 & 0.534949 \\
7 & 89.61 & 0.474844 & 91.34 & 0.41825 & 90.75 & 0.443816 \\
8 & 89.99 & 0.461878 & 89.52 & 0.474101 & 91.52 & 0.416571 \\
9 & 89.77 & 0.467551 & 90.85 & 0.430233 & 90.73 & 0.4428 \\
\hline Min & 87.48 & 0.461878 & 86.22 & 0.41825 & 87.56 & 0.416571 \\
Max & 89.99 & 0.785791 & 91.34 & 0.860958 & 91.52 & 0.667375 \\
\hline
\end{tabular}

Values for the network parameters that were achieved from the training phase are shown in Table 4. As for data set 7, the total epoch is 21 and the best result achieved was with both learning rate (LR) and momentum (Mom) equal to 0.2. The best network architecture achieved is 24-15-3.

Table 4. Neural Network Parameters

\begin{tabular}{ccccccc}
\hline Data Set & Epoch & \#Input & \#hidden unit & \#output unit & LR & Mom \\
\hline 1 & 88 & 6 & 31 & 3 & 0.7 & 0.5 \\
2 & 91 & 9 & 35 & 3 & 0.4 & 0.4 \\
3 & 39 & 12 & 21 & 3 & 0.5 & 0.2 \\
4 & 21 & 15 & 7 & 3 & 0.3 & 0.1 \\
5 & 46 & 18 & 3 & 3 & 0.3 & 0.1 \\
6 & 21 & 21 & 5 & 3 & 0.3 & 0.1 \\
7 & 21 & 24 & 15 & 3 & 0.2 & 0.2 \\
8 & 21 & 27 & 23 & 3 & 0.1 & 0.3 \\
9 & 21 & 30 & 21 & 3 & 0.2 & 0.1 \\
\hline
\end{tabular}




\subsection{Decision Model}

The results of neural network training, validation, and testing for the decision model are shown in Table 5. Overall, the lowest error achieve for training, validation and testing was $0.065795,1.59 \mathrm{E}-07$, and $9 \mathrm{E}-10$ respectively. The best results of training, validation, and testing was $98.35 \%, 100 \%$, and $100 \%$ respectively. These results show that neural network classifier has performed very well on temporal data set. Based on the results in Table 3, data set 4 is chosen to be the best data set. Neural network train with data set 4 achieves $93.94 \%$ of training performance and $100 \%$ of validation and testing performance. The error was $0.23505,0.023383$, and 0.007085 respectively. Data set 4 was formed with window size 5 with 82 instances.

Table 5. Results of Training, Validation and Testing

\begin{tabular}{ccccccc}
\hline \multirow{2}{*}{ Data Set } & \multicolumn{2}{c}{ Training } & \multicolumn{2}{c}{ Validation } & \multicolumn{2}{c}{ Testing } \\
& $\%$ & Error & $\%$ & Error & $\%$ & Error \\
\hline 1 & 90.00 & 0.39996 & 87.50 & 0.5 & 100.00 & $9 \mathrm{E}-10$ \\
2 & 90.91 & 0.362563 & 100.00 & 0.007216 & 100.00 & $6.13 \mathrm{E}-05$ \\
3 & 95.62 & 0.147186 & 85.72 & 0.626408 & 100.00 & 0.034537 \\
4 & 93.94 & 0.23505 & 100.00 & 0.023383 & 100.00 & 0.007085 \\
5 & 89.34 & 32.00295 & 100.00 & $1.59 \mathrm{E}-07$ & 100.00 & $1.4 \mathrm{E}-07$ \\
6 & 97.70 & 0.092475 & 95.46 & 0.188657 & 100.00 & 0.002146 \\
7 & 98.35 & 0.065796 & 100.00 & 0.032103 & 95.46 & 0.191186 \\
8 & 93.09 & 0.276602 & 95.84 & 0.166669 & 95.84 & 0.168359 \\
9 & 97.37 & 0.104647 & 95.84 & 0.171619 & 100.00 & 0.003985 \\
\hline Min & 89.34 & 0.065795 & 85.72 & $1.59 \mathrm{E}-07$ & 95.455 & $9 \mathrm{E}-10$ \\
Max & 98.35 & 32.00295 & 100 & 0.626408 & 100 & 0.191186 \\
\hline
\end{tabular}

Values for the network parameters that were achieved from the training phase are shown in Table 6. As for data set 4, the total epoch is 86 and the best result achieved was with learning rate (LR) 0.8 and momentum (Mom) 0.2. The best network architecture achieved is $8-23-2$.

Table 6. Neural Network Parameters

\begin{tabular}{ccccccc}
\hline Data Set & Epoch & \#Input & \#Hidden Unit & \#Output Unit & LR & Mom \\
\hline 1 & 77 & 5 & 25 & 2 & 0.9 & 0.4 \\
2 & 42 & 6 & 23 & 2 & 0.8 & 0.4 \\
3 & 33 & 7 & 17 & 2 & 0.7 & 0.3 \\
4 & 86 & 8 & 23 & 2 & 0.8 & 0.2 \\
5 & 31 & 9 & 9 & 2 & 0.9 & 0.8 \\
6 & 31 & 10 & 7 & 2 & 0.7 & 0.5 \\
7 & 54 & 11 & 5 & 2 & 0.5 & 0.5 \\
8 & 42 & 12 & 25 & 2 & 0.4 & 0.8 \\
9 & 27 & 13 & 9 & 2 & 0.4 & 0.6 \\
\hline
\end{tabular}




\section{Discussion}

The sliding window technique has been successfully applied on reservoir water level data to extract and segment the data to preserve the temporal relationship of the data. It was shown in Table 1 that the size of window has influence the number of usable instances. The bigger the window size the larger the usable instances. The large number of usable instances will contains large number of temporal patterns that can be used for neural network modeling. The large size of data is vital as the performance of neural network model is highly influenced by the size of data set. However, as the data size increase the number of input also increase. The large number of input unit will increase the complexity of the neural network modeling.

The finding of this study also suggests that 8 days are the best time duration for the delay. This suggests that 8 days observation of the upstream rainfall will significantly increase the water level at the reservoir. Additionally, 5 days of observed water level changes has been found to be significant of the reservoir water release decision. This information is vital for reservoir management to plan early water release.

The reservoir water level data typically the current, the (expected) tomorrow water level and the changes of water level are extracted from the reservoir operation record. In actual reservoir operation and decision making, the current water level represent the current stage of reservoir water level $(t)$, while the tomorrow water level is water level that is expected for tomorrow at $t+1$. As shown in this paper, the water level can be forecasted based hydrological variables. The changes of reservoir water level represent the increase or decrease of reservoir water level. Observing the changes of reservoir water level at time $t$ and the preceding $t-1, t-2, \ldots, t-w$ will give an insight on when to release the reservoir water.

\section{Conclusion}

The findings of this study can be used to aid reservoir water release decision. Typically, reservoir water release decision was influenced by the upstream rainfall. Since upstream rainfall was recorded through upstream gauging stations which are located quite far from the reservoir and river water might be lost due to environmental factors, the time delay is expected before the rain water can give effect to the reservoir water level. In this study, window sliding has been shown to be a successful approach to model the time delays, while neural network was shown as a promising modelling technique.

Manually, reservoir operator monitors the changes of water level and consults the superior officer before taking the appropriate action. Having unpredicted circumstances of the weather, early decision of the reservoir water release is always a difficult decision. Information on the delay and the forecasted reservoir water level can be used by reservoir operator to decide early water release. Early water release of the reservoir will reserve enough space for incoming inflow due to heavy upstream rainfall. In addition, the water release can be controlled within the capacity of the downstream river. Thus flood risk downstream due to extreme water release from the reservoir can be reduced. 
Acknowledgments. The authors' most appreciation to the Perlis Department of Drainage and Irrigation for permission and supplying Timah Tasoh reservoir operational data.

\section{References}

1. Gaynor, M., Seltzer, M., Moulton, S., Freedman, J.: A Dynamic, Data-Driven, Decision Support System for Emergency Medical Services. In: Sunderam, V.S., van Albada, G.D., Sloot, P.M.A., Dongarra, J. (eds.) ICCS 2005. LNCS, vol. 3515, pp. 703-711. Springer, Heidelberg (2005)

2. Philips-Wren, G.: Adaptive Decision Support for Dynamic Environments. New Ad-vances in Intelligent Decision Technologies 199, 235-243 (2009)

3. Feigh, K., Pritchett, A.: Design of Support Systems for Dynamic Decision Making in Airline Operations. In: Proceedings of the 2006 Systems and Information Engineering De-sign Symposium, pp. 136-141 (2006)

4. Sinha, R.: Impact of Experience on Decision Making in Emergency Situation. Psychol-ogy C/D: Extended Essay. Department of Human Work Sciences, Lulea University of Technology (2005)

5. Simonovic, S.P.: Decision support system for flood management in the Red River Basin. Canadian Water Resources Journal 24(3), 203-223 (1999)

6. Smith, K., Ward, R.: Floods: Physical Processes and Human Impacts. John Wiley, England (1998)

7. Jain, S.K., Singh, V.P.: Reservoir Operation. In: Jain, S.K., Singh, V.P. (eds.) Water Resources Systems Planning \& Management, ch.11, vol. 51, pp. 615-679. El-sevier B. V, Amsterdam (2003)

8. Chang, T.J., Kleopa, X.A., Teoh, C.B.: Use of Flood-Control Reservoirs for Drought Management. Journal of Irrigation and Drainage Engineering 121(1), 34-42 (1995)

9. IFRC Annual Report 2007. International Federation of Red Cross and Red Crescent Societies (2007)

10. Tucci, C.E.M.: Flood Flow Forecasting. Presented at 54th Session of Executive Coun-cil of WMO World Meteorological Organization, Geneva (2002)

11. Federal Emergency Management Agency. Flood Insurance: The Right Choice: NFIP Fact Sheet 2008. Federal Emergency Management Agency, U.S. Department of Home-land Security (2008)

12. Baldwin County Planning and Zoning Department. Exploring the Baldwin County Flood Zoning Plan and the Benefits of Flood Hazard Mitigation. White Paper. Baldwin County Commission, Alabama (2007)

13. Manusthiparom, C., Apirumanekul, C., Mahaxay, M.: Flood Forecasting and River Monitoring System in the Mekong River Basin. Second Southeast Asia Water Forum (2005)

14. Technical Support Unit. Integrated Flood Management. APFM Technical Document No. 1 (2nd), The Associated Programme on Flood Management. (2004)

15. Wurbs, R.A.: Reservoir-System Simulation and Optimization Models. Journal of Water Resources Planning and Management 119(4), 455-472 (1993)

16. Calenda, G., Mancini, C.P.: The Role of the Corbara Reservoir on the Tiber River in the Flood Protection of the Town of Rome, Italy. In: Brookshie, P.A. (ed.) Proceedings of Waterpower Conference, ASCE Research Library (1999) 
17. Zhou, F., Yang, B., Li, L., Chen, Z.: Overview of the New Types of Intelligent Decision Support System. In: Proceedings of International Conference on Innovative Computing Information and Control, p. 267 (2008)

18. Russell, S., Norvig, P.: Artificial Intelligence: A Modern Approach, 2nd edn. Pearson Education Inc., New Jersey (2003)

19. Guerlin, S., Brown, D.E., Mastrangelo, C.: Intelligent Decision Support Systems. In: IEEE International Conference on Systems, Man and Cybernetics, vol. 3, pp. 1934-1938 (2000)

20. $\mathrm{Hu}, \mathrm{T} . \mathrm{S} ., \mathrm{Lam}, \mathrm{K} . \mathrm{C} ., \mathrm{Ng}, \mathrm{S} . \mathrm{T} .:$ River flow time series prediction with a range-dependent neural network. Hydrohgical Sciences 46(5), 729-745 (2001)

21. Dibike, Y.B., Solomatine, D.P.: River flow forecasting using artificial neural networks. Physics and Chemistry of the Earth, Part B: Hydrology, Oceans and Atmosphere 26(1), $1-7(2001)$

22. Chang, F.-J., Chen, Y.-C.: A Counterpropagation Fuzzy-Neural Network Modeling Approach to Real Time Streamflow Prediction. Journal of Hydrology 245, 153-164 (2001)

23. Kisi, O.: River Flow Modeling Using Artificial Neural Networks. Journal of Hydrologic Engineering 9(1), 60-63 (2004)

24. Coulibaly, P., Anctil, F., Bobee, B.: Daily reservoir inflow forecasting using artificial neural networks with stopped training approach. Journal of Hydrology 230, 244-257 (2000)

25. Coulibaly, P., Anctil, F., Bobee, B.: Multivariate Reservoir Inflow Forecasting using Temporal Neural Networks. Journal of Hydrologic Engineering 6(5), 367-376 (2001)

26. Chang, F.-J., Chang, Y.-T.: Adaptive Neuro-Fuzzy Inference System for Prediction of Water Level in Reservoir. Advances in Water Resources 29, 1-10 (2006)

27. Lobbrecht, A.H., Solomatine, D.P.: Control of water levels in polder areas using neural networks and fuzzy adaptive systems. Water Industry Systems: Modelling and Optimization Applications 1, 509-518 (1999)

28. Solomatine, D.P., Xue, Y.: M5 Model Trees and Neural Networks: Application to Flood Forecasting in the Upper Reach of the Huai River in China. Journal of Hydrologic Engineering 9(6), 1-10 (2004)

29. Kumar, A.R.S., Jain, S.K., Agarwal, P.K.: Application of Artificial Neural Networks (ANN) in Reservoir Operation. Technocal Report No. TR/BR-6/1999-2000, National Institute of Hydrology, India (1999)

30. Chaves, P., Chang, F.-J.: Intelligent Reservoir Operation System Based on Evolving Artificial Neural Networks. Advances in Water Resources 31, 926-936 (2008)

31. Ku-Mahamud, K.R., Zakaria, N., Katuk, N., Shbier, M.: Flood Pattern Detection Using Sliding Window Technique. In: Third Asia International Conference on Modeling \& Simula-tion, pp. 45-50 (2009)

32. Chong, C.C., Jia, J.C.: Assessments of neural network output codings for classification of multispectral images using Hamming distance measure. In: Proceedings of the 12th IAPR International Conference on Pattern Recognition, vol. 2, pp. 526-528 (1994)

33. Sarle, W.: Stopped Training and Other Remedies for Overfitting. In: Proceedings of the 27th Symposium on the Interface of Computing Science and Statistics, pp. 352-360 (1995) 